\title{
Use of Potentials in Linear Programming Models
}

\author{
Irek Mustaev \\ dept. of management of \\ innovations \\ Ufa State Aviation Technical \\ University \\ Ufa, Russian Federation \\ fermi_moustaev@mail.ru
}

\author{
Vladimir Ivanov \\ dept. of innovations and \\ perspective programs, \\ UEC-UMPO, DBA-Engineering \\ Ufa, Russian Federation \\ ivanov.vladimir@mail.ru
}

\author{
Murat Guzairov \\ dept. of computing and \\ information security \\ Ufa State Aviation Technical \\ University \\ Ufa, Russian Federation \\ mbguzairov@gmail.com
}

\author{
Timur Mustaev \\ Ufa State Aviation Technical \\ University \\ Ufa, Russian Federation \\ tima.mus.1321@gmail.com
}

\begin{abstract}
The article describes a modified Kantorovich model based on the use of accumulated potentials. Accumulated and predicted potentials are described in detail in previous works by the authors. A real-life example illustrates the benefits of modeling using potentials. It is shown, in particular, that the use of accumulated potentials significantly reduces the uncertainty of the model. This broadens the horizons for using linear optimization models. This allowed us to formulate a modified linear optimization Kantorovich's model. The model is the basis of a well-known resource planning scheme. In order to be able to use this scheme, additional research was conducted. A model of the effectiveness of the resources based on accumulated potentials was formulated in particular. The formula for calculating the normative time of production operations was obtained also. In addition, a model for the formation of a production program based on accumulated potentials is described. Corresponding indicators and their dimensions are given.
\end{abstract}

Keywords-Linear programming, optimization, accumulated potential.

\section{INTRODUCTION}

Modeling the production and operation of high-tech products in order to find ways to increase efficiency requires optimization. There are a variety of optimization techniques and operations research. Linear programming method developed by Kantorovich L.V., Dantzig G.B. [1, 2, 3, 4], was widely used until recently $[9,10,11]$. However, the changes associated with the transition from a centrally planned to a market economy have significantly reduced interest in these methods.

The conditions of existence of enterprises, their characteristics vary significantly over relatively short periods of time. Uncertainty is also associated with increased volatility of consumer requirements for goods. From a mathematical point of view, this leads to uncertainty in the coefficients of the optimization model and, as a result, to erroneous conclusions drawn from the analysis of the simulation results.

Modern approaches to the creation of competitive scienceintensive products suggest the creation and implementation of management systems for them throughout the whole life cycle from design to disposal, including the stages of creation and operation. The high life-cycle duration, reaching several decades, further exacerbates the problem of uncertainty, because over this time the characteristics of all elements of the proposed life-cycle management system change significantly and indeterminably [5]. Thus, the significant volatility of all properties and characteristics of the elements of the life-cycle management system of a science-intensive product throughout its existence time is, in our view, one of the obstacles to the widespread use of optimization methods and, specifically, the linear programming method.

The solution of the problem may relate to the implementation of approaches based on the modeling of the formalized parameters of the analyzed object - its potentials. From the methodological point of view, it is about changing the paradigm of analysis and management from the process approach to the object approach. From the point of view of analysis, the simulation of processes is generalized to the simulation of the dynamics of the state of the object under study. Features of the dynamics of potentials allow to return to use of optimization approaches, one of which is the Kantorovich linear programming method, but in the terminology of potential optimization. From a utilitarian point of view, this means extending the scope of the linear programming methodology to the study of the behavior of socioeconomic systems in market conditions

\section{PROBLEM DEFINITION}

It is known that the abstract model of L.V. Kantorovich concerning the optimal use of resources by a complex system involves a primal and a dual problem and is formalized as follows [1]. Suppose that production uses $m$ types of resources to produce $\mathrm{n}$ product types. It is assumed that the volume constraints for the use of these resources $b_{1}, b_{2}, \ldots, b_{m}$ are known. In addition, the following indicators should be known: specific consumption $a_{i j}$ of resource $i$ per output unit $j$, product unit price $c_{j}$.

\section{Primal problem of Kantorovich (C).}

It is true (1), if products are made consisting of $j=$ $1,2, \ldots, n$ parts of volume $x_{j}, j=1,2, \ldots, n$. The first of the relations in system (1) represents a restriction on the utility 
function, which can be interpreted as follows: the goal of products output is to ensure the maximum possible value of its price. The following relations in (1), written in the form of a system of inequalities, reflect the understanding that only existing resources can be used in production.

$$
(C)\left\{\begin{array}{l}
f(x)=\sum_{j=1}^{n} c_{j} x_{j} \rightarrow \max \\
\sum_{j=1}^{n} a_{i j} x_{j} \leq b_{i}, i=1,2, \ldots, m \\
x_{j} \geq 0, j=1,2, \ldots, n
\end{array}\right.
$$

The Kantorovich conjugate dual model $\left(C^{*}\right)$ is formalized as follows in the form of the system (2):

$$
\left(C^{*}\right)\left\{\begin{array}{l}
\phi(y)=\sum_{i=1}^{m} b_{i} y_{i} \rightarrow \min \\
\sum_{i=1}^{m} a_{i j} y_{i} \geq c_{j}, j=1,2, \ldots, n \\
y_{i} \geq 0, i=1,2, \ldots, n
\end{array}\right.
$$

Here $y_{i}$ is the estimate (price) of the $j-t h$ resource under its alternative use. The first of the limitations in (2) reflects the goal of optimal use of resources: the overall estimate (price) of the resources used should be minimal. The following $n$ inequalities reflect the result of comparing the use of resources for output of products at the enterprise or their sale to a third party (alternative use of resources): an enterprise selling resources should receive revenue $\sum a_{i j} y_{i}$ not less than that which it can receive from manufacturing products $c_{j}$.

Integral characteristics and properties of the object, called accumulated, forecasted and total (own) potentials and, accordingly, the accumulated, forecasted and own states of the object are formalized as follows [6, 7]. Let us fix the current time $t$. Suppose that in the past, at the time $(t-\tau)$ a single payment was made with the value $q(t-\tau)=q_{0}$. In order for the payment, having been invested in market instruments in the past at time $(t-\tau)$, to lead to the current value of the asset, i.e. to $q_{0}$ at time $t$, it must be equal to:

$$
X_{q}^{a}(t, \alpha, \sigma)=q(t-\tau) \cdot \psi(\tau, \alpha, \sigma)=q_{0} \cdot \psi(\tau, \alpha, \sigma) .
$$

Here, $\psi$ is the sociophysical function of a system that includes an object as a control object, $\alpha$ the amount of profitability that has developed over the time interval $(t-\tau, t)$ risk. The value $X_{q}^{a}$ is called accumulated payment potential and has the meaning of the current market valuation of the single payment made in the past. The accumulated potential of the flow of payments made in the past is determined by the formula:

$$
X_{q}^{a}(p, t)=\int_{\tau=0}^{\infty} q(t-\tau) \cdot \psi(\tau, p) d \tau=\widehat{\mathrm{A}} q
$$

In (3), the complex variable $p$ is formed from two functions $\lambda$ and $v$ as follows: $p=\lambda(\alpha)+j v(\sigma)$. The function $\lambda$ is called a function of profitability, $v-$ a function of uncertainty. Formula (3) is used to determine the accumulated potential of any object state variable, and not just cash flows. In aggregate, the accumulated potentials of state variables characterize the accumulated potential of the object. The state of the object is defined as the accumulated state. Thus, the accumulated state of the object is put in line with its accumulated potential. The function $\psi$, called a sociophysical function, is presented with requirements similar to those required during the market valuation of flows and assets, namely: $|\psi(t, p)| \rightarrow 0$, if $t \rightarrow \infty$; $\psi(t, p)=0$, with $t<0$; the norm is limited by $\|\psi\|=1$; the function q must be quadratically integrable over time: $q \in L^{2}$.

The forecasted potential is defined as follows. Suppose that with respect to the current time $t$, in the future, at the time $(t+\tau)$ a single payment $q(t+\tau)$ is forecasted. Market valuation of the payment value is determined from the relation:

$$
X_{q}^{f}(t, \alpha, \sigma)=q(t+\tau) \cdot \psi_{\ni \kappa}(\tau, \alpha, \sigma)
$$

For a future flow consisting of an arbitrary number of payments $q(t+\tau), \tau \in(0, \infty)$ the market value appraisal at time $t$ is determined from the relation:

Formulas (4) and (5), which are formulas for calculating present values [8], are used for generalization in cases of variables q of any types, and not just cash flows. In this case, the discounting function $\psi_{\text {эк }}=1 /(1+f(\alpha, \sigma))$ is generalized to the sociophysical function $\psi$, described above: $\psi_{\text {эк }} \rightarrow \psi$. The state in which the object is at time $t$, is called the forecasted state. The forecasted state of the object is aligned with its forecast potential.

The total (own) flow potential is defined as the sum of two potentials: the accumulated potential, determined by formula (3), and the forecasted potential, determined by formula (5):

$$
X_{q}=X_{q}^{a}+X_{q}^{f}=\widehat{C} q
$$

The total potential corresponds to a state called the own state of the object.

The simulation results illustrating the transition from the process scheme to the simulation of states using potentials are shown in Fig. 1 and Fig. 2. Fig. 1 shows the revenue and balance charts of a Russian aviation enterprise, built on quarterly observations over a long period -12 years. Fig. 2 shows the ratio of the accumulated potentials calculated by formula (3). 


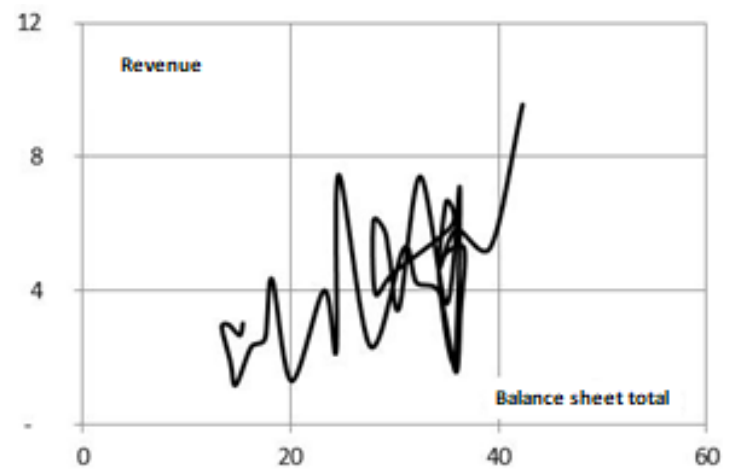

Fig. 1. Revenue and balance sheet total of one of the Russian aviation sector enterprises over 12 years

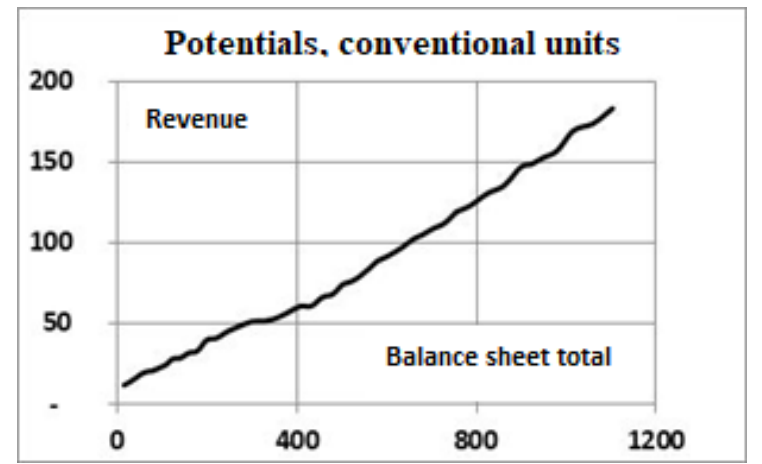

Fig. 2. Accumulated potentials of revenue and balance sheet total of one of the Russian aviation sector enterprises over 12 years)

To formalize the Kantorovich model, it is necessary to preliminarily determine a number of models that will be described in relation to the accumulated form of the potential.

\section{III. . THEORY}

\section{A. Model of efficiency with the use of accumulated potentials}

Let us consider the following example. An enterprise purchases a machine for 15000 conventional monetary units. Assume that the annual costs of $4000 \frac{\text { conventional units }}{\text { year }}$, associated with the use of the $B_{i}$ machine in production and the wholesale price of the product $A_{j} 8000 \frac{\text { conventional units }}{\text { year }}$, obtained on this machine are known. An annual market yield of $25 \%$ is assumed. A total of $N$ pcs of parts are produced in a year. The wholesale price of the products received on the machine is $9000 \frac{\text { conventional units }}{\text { year }}$. These data are sufficient to determine the dynamics of the change in the efficiency $r_{i j}^{\prime}$ of the use of the machine, determined by the ratio of accumulated production potentials $X_{\text {income }_{i j}}$ and costs $X_{\text {costs }_{i j}}$ in unit time:

$$
\begin{aligned}
& r_{i j}^{\prime}(t)=\frac{\Delta X_{\text {income }_{i j}}(t)}{\Delta X_{\cos t s_{i j}}(t)}, \\
& \Delta X_{\text {income }_{i j}}(t)=\Delta X_{\text {income }_{i j}}(t+\Delta t)-\Delta X_{\text {income }_{i j}}(t), \\
& \Delta X_{\cos t s_{i j}}(t)=\Delta X_{\cos t s_{i j}}(t+\Delta t)-\Delta X_{\cos t s_{i j}}(t) .
\end{aligned}
$$

It should be noted that the efficiency of the machine, determined by (6), differs from the efficiency, determined as usual, as a ratio of income and costs. For this example, modeling shows that the efficiency, determined by the initial values of income and costs, exceeds the estimated value, determined by potential, by $10 \%$ (2.2 conventional units vs. 2.0 conventional units). Indeed, the emerging pattern of revenues and costs, reflected in real costs and revenues, has an additional effect on the corresponding potentials and, as a consequence, on the efficiency $r_{i j}^{\prime}(t)$ in (6). Let us consider the proposed example under conditions with other indicators of income and costs. Suppose that the enterprise's revenues, on average, decreased by $20 \%$ and amounted to $7200 \frac{\text { conventional units }}{\text { year }}$. The machine efficiency index, determined by (6), will decrease against the calculated value determined by the passport data by $40 \%$ to 1.7 units. The example illustrates the possibility of considering changes in environmental parameters and payments when using accumulated potentials.

In addition to the efficiency index $r_{i j}^{\prime}(t)(6)$, it is possible to use the efficiency index, calculated through the ratio of the increments of the income and cost potentials, i.e. of net income:

$$
r_{i j}(t)=\frac{\Delta X_{\text {income }_{i j}}(t)-\Delta X_{\cos t t_{i j}}(t)}{\Delta X_{\cos t s_{i j}}(t)}=r_{i j}^{\prime}(t)-1 .
$$

The informativeness of the performance indicators Ошибка! Источник ссылки не найден. and (1) relates to the fact that the following factors are considered:

- first, real, not passport production;

- secondly, the actual picture of the activity of the enterprise on which the equipment is used

\section{B. Model of efficiency with the use of accumulated potential Model of determining the norm of time in terms of potentials}

The classical formulation of the problem requires the determination of the coefficients of the model $\square$ time norms to produce 1 part. Accordingly, it is possible to determine several indicators similar to the technological indicator of the time norm for processing products on the machine but determined by potential.

The time norm to receive 1 ruble of income potential on a time interval $\left(t_{0}, t_{1}\right)$ from the manufacture of $j-t h$ parts on $i-t h$ machine - «potential time norm»: 


$$
a_{\text {income }_{i j}}^{\prime}=\frac{t_{1}-t_{0}}{X_{\text {income }_{i j}}\left(t_{1}\right)-X_{\text {income }_{i j}}\left(t_{0}\right)},\left[\text { rubles }^{-1}\right]
$$

The introduction of this and other indicators is related to the idea that the specified technical characteristics of the machine its passport performancies - correspond to the average, distinctive for each enterprise, efficiency of its use, depending on the organization of production, the economic state of the enterprise as a whole, etc. In other words, the machine and with it every detail manufactured on it are considered as sociotechnical systems, the external environment for which is an enterprise with its individual characteristics. Knowing the coefficient $a_{i j}^{\prime}$ allows us to determine that the desired result the increment of the income potential by the amount $\Delta X_{\text {income }_{i j}}$ - can be obtained if we spend $a_{\text {income }_{i j}}^{\prime} \cdot \Delta X_{\text {income }_{i j}}$ units time. Analogously to the coefficient of the "potential norm of time" $a_{\text {income }_{i j}}^{\prime}$ defined by the income potentials, we can write the coefficients of the "potential norms" $a_{\text {costs }}^{\prime}{ }_{i j}$ ' and $a_{i j}^{\prime}$, defined for the potentials of costs and net income, respectively:

$$
\begin{gathered}
a_{\cos t s_{i j}}^{\prime}=\frac{t_{1}-t_{0}}{X_{\cos t s_{i j}}\left(t_{1}\right)-X_{\cos t s_{i j}}\left(t_{0}\right)},\left[\text { rubles }^{-1}\right], \\
a_{i j}^{\prime}=\frac{t_{1}-t_{0}}{X_{i j}\left(t_{1}\right)-X_{i j}\left(t_{0}\right)},\left[\text { rubles }^{-1}\right] .
\end{gathered}
$$

Knowledge of these norms allows to determine the time spent at a particular workplace, to obtain the required income, with the expenditure of funds (costs) and to obtain net income. Namely, to obtain the $\varphi$ rubles of revenue potential in the existing organizational and technical conditions, approximately $\Delta T=\varphi \cdot a_{\text {income }_{i j}}$ of time units are spent, making $j$ parts on the $i-t h$ machine. Using the coefficients $a_{\text {costs }_{i j}}^{\prime}$ and $a_{i j}^{\prime}$ allows to determine the same time using potentials of costs and net incomes. Denoting the potentials as $\varphi$, in both cases, we obtain that the formulas will look as follows:

$$
\begin{gathered}
\Delta T=\varphi \cdot a_{\cos t s_{i j}}^{\prime}, \\
\Delta T=\varphi \cdot a_{i j}^{\prime} .
\end{gathered}
$$

If the production time norm $\tau_{i j}$, [units time/piece] is known, it is possible to determine the coefficient of «potential intensiveness» $p_{\text {income }_{i j}}^{\prime}$ may be determined. If calculations are made for income potentials, then:

$$
\begin{aligned}
p_{\text {income }_{i j}} & =\frac{\tau_{i j}}{a_{\text {income }_{i j}^{\prime}}}\left[\frac{\text { rubles } \cdot \text { units time }}{\text { piece }}\right]= \\
& =\frac{\tau_{i j}}{a_{\text {income }_{i j}}^{\prime}}\left[\frac{\text { units of potensial }}{\text { piece }}\right]
\end{aligned}
$$

In formula (8), it is taken into account that the dimension of the potential is equal to [units of potential $]=[$ rubles . units time], then taking into account this fact, according to the coefficients $a_{\text {costs }}^{\prime}$ and $a_{i j}^{\prime}$ the coefficient of «potential intensiveness» $p^{\prime}{ }_{\text {costs }}$ ij may be determined if calculations are made for cost potentials and the coefficient of «potential intensiveness» $p_{i j}^{\prime}$, may be determined if calculations are made for net income potentials:

$$
\begin{aligned}
p_{\cos t s_{i j}}^{\prime} & =\frac{\tau_{i j}}{a_{\cos t s_{i j}}^{\prime}}\left[\frac{\text { rubles } \cdot \text { units time }}{\text { piece }}\right]= \\
& =\frac{\tau_{i j}^{\prime}}{a_{\cos t s_{i j}^{\prime}}^{\prime}}\left[\frac{\text { units of potensial }}{\text { piece }}\right], \\
p_{i j}^{\prime} & =\frac{\tau_{i j}}{a_{i j}^{\prime}}\left[\frac{\text { rubles } \cdot \text { units time }}{\text { piece }}\right]= \\
& =\frac{\tau_{i j}}{a_{i j}^{\prime}}\left[\frac{\text { units of potensial }}{\text { piece }}\right] .
\end{aligned}
$$

Thus, to receive $\varphi$ [units of potential] of income potential it is necessary to produce the following amount of $j$ parts on the $i-t h$ machine:

$$
q_{i j}=\varphi \cdot \frac{a_{\text {income }_{i j}^{\prime}}}{\tau_{i j}}=\frac{\varphi}{p_{\text {income }_{i j}}^{\prime}},[p c s] .
$$

If, as above, $\varphi$ denotes the potentials of costs or net incomes, then the formulas for determining the number of parts produced through the coefficients of the "potential intensiveness" $p_{\text {costs }_{i j}}$ and $p_{i j}^{\prime}$ will look as follows:

$$
\begin{gathered}
q_{i j}=\varphi \cdot \frac{a_{\cos t s_{i j}^{\prime}}}{\tau_{i j}}=\frac{\varphi}{p_{\cos t s_{i j}^{\prime}}},[p c s] \\
q_{i j}=\varphi \cdot \frac{a_{i j}^{\prime}}{\tau_{i j}}=\frac{\varphi}{p_{i j}^{\prime}},[p c s]
\end{gathered}
$$

The inconvenience associated with the dimension of the potential [units of potential $]=[$ rubles $\cdot$ units time $]$ is overcome if all potential calculations are carried out in a single time base of 1 [units time]. In this case, the numerical expression of the potential will correspond to its ruble expression. It should be emphasized that the potential of products produced on the machine is determined by the accumulated potentials of income $X_{\text {income }_{i j}}(t)$ and costs $X_{\text {costs }_{i j}}(t)$, associated with this product. It follows from relations (9) - (13) that the increase in the potential for the production of $q_{i j}$ units of production by using different potentials will be:

$$
\varphi=p_{\text {income }_{i j}}^{\prime} \cdot q_{i j}
$$


or

$$
\varphi=p_{\cos t s_{i j}}^{\prime} \cdot q_{i j}
$$

or

$$
\varphi=p_{i j}^{\prime} \cdot q_{i j} .
$$

The illustration of the Kantorovich optimization model using potentials is carried out using the example of the accumulated potentials of the object under study.

\section{Model of calculation of production programme using potentials}

The informal description of the problem is as follows. The production $A_{j}, j=1,2, \ldots, n$ is processed on the machines $B_{i}, i=1,2, \ldots, m$ with known per-piece time expenditure rate to create 1 ruble of net income potential. Let us introduce the following notation:

$$
\begin{gathered}
i \text { - machine number } i=1,2, \ldots, m ; \\
j \text { - product number, } j=1,2, \ldots, n
\end{gathered}
$$

$a_{i j}$ - time norm to receive 1 ruble of potential when producing 1 piece of $j-t h$ product on $i-t h$ machine;

$\tau_{i j}-$ known time rate of production of $j-t h$ part on $i-t h$ machine;

$c_{i}-$ net income potential operating the $i-t h$ machine;

$x_{j}-$ number of produced parts of $j-t h$ type

The production of $j-t h$ type of parts on $i-t h$ machine in number of $x_{i j},[p c s]$ leads to an increase in the potential by:

$$
\begin{aligned}
\varphi & =x_{i j} \frac{\tau_{i j}}{a_{i j}},[\text { rubles } \cdot \text { units time }]= \\
& =x_{i j} \frac{\tau_{i j}}{a_{i j}},[\text { units of potensial }] .
\end{aligned}
$$

Limitations on the work time fund of machines are described as the restriction $\Phi_{i}$ for the time of $i-t h$ machine operation. In other words, the production time of $x_{i j}$ parts on the $i-t h$ machine is limited by time $\Phi_{i}$.

The objective function, written using the potentials in accordance with (14), has the following interpretation: production must be organized so as to maximize the resulting potential:

$$
\sum_{i, j} x_{i j} \frac{\tau_{i j}}{a_{i j}} \rightarrow \max ,[\text { rubles } \cdot \text { units time }]
$$

$$
\sum_{i, j} x_{i j} \frac{\tau_{i j}}{a_{i j}} \rightarrow \max ,[\text { units of potensial }] \text {. }
$$

The increase of potential can be associated not only with the increase in volumes, but also with a decrease in the time norm $a_{i j}$ for obtaining potential in the production of products on the machine. Bearing in mind that this norm takes into account not only the organization of production at the enterprise itself, but also the external conditions, it turns out that criterion (15) - (16), as noted, provides a solution to the optimization problem under changing external conditions, i.e. in the market environment. Additional restrictions are associated with the requirement of positive production volumes:

$$
x_{i j} \geq 0,[p c s], j=1,2, \ldots, n \text {. }
$$

Equations (15) - (17) complete the formation of a model for calculating the production program of an enterprise - the Kantorovich model $\left(C^{\prime}\right)$ recorded using potentials:

$$
\left(C^{\prime}\right)\left\{\begin{array}{l}
\sum_{i, j} x_{i j} \frac{\tau_{i j}}{a_{i j}} \rightarrow \max \\
\sum_{j=1}^{n} \tau_{i j} x_{i j} \leq \Phi_{i}, i=1, .2, . ., m \\
x_{i j} \geq 0, j=1,2, \ldots, n
\end{array}\right.
$$

Taking into account the introduced notation for the potential intensiveness, we obtain:

$$
\left(C^{\prime \prime}\right)\left\{\begin{array}{l}
\sum_{i, j} p_{i j} x_{i j} \rightarrow \max \\
\sum_{j=1}^{n} \tau_{i j} x_{i j} \leq \Phi_{i}, i=1,2, \ldots, m \\
x_{i j} \geq 0, j=1,2, \ldots, n
\end{array}\right.
$$

or

$$
\left(C^{\prime \prime \prime}\right)\left\{\begin{array}{l}
\sum_{i, j} P_{j} x_{j} \rightarrow \max \\
\sum_{j=1}^{n} \tau_{i j} x_{i j} \leq \Phi_{i}, i=1,2, \ldots, m \\
x_{i j} \geq 0, j=1,2, \ldots, n
\end{array}\right.
$$

Here the notation $P_{j}=\sum_{i} p_{i j}$ used to determine the "potential intensiveness" of the whole series of machines producing the $j-t h$ part. The optimization task is to find a 
programme for the parts production that will provide the greatest aggregate product potential.

\section{CONCLUSION}

The proposed article shows the possibility of using the accumulated potentials in the linear programming model. In addition, auxiliary models of efficiency of use, determination of time norms and calculation of a production programme using potentials are described. For forecasted and complete forms of potential, the formulation of the problem is analogous.

\section{REFERENCES}

[1] Gizatullin Kh.N., Rizvanov D.A. The problems of managing complex socio-economic systems / Ed. By Tatarkin A.I.; RAS, Ural branch, Institute of economics. Moscow: ZAO «Economica Publishing House», 2005.-p.218. (in Russian).

[2] Kantorovich L.V. Selected Works. Gordon and Breach, London etc. (1996) (Parts 1 and 2).
[3] Dantzig G.B. Programming of independent activities. Pt.II. Mathematical model / G.B. Dantzig // Econometrica. - 1949. - № 17. p.200-211.

[4] Dantzig G.B. Linear Programming and Extensions. Princeton University Press, Princeton (1963) (Parts 1 and 2), P. 22-33.

[5] Alchian A. Uncertainty, Evolution and Economic Theory//Journal of Political Economy, 1950, v. 58, p.211-221.

[6] Mustaev I.Z. Economic models of theory of innovations: Monograph. Ufa: RIK UGATU, 2013.-p.202. (in Russian)

[7] Moustaev I.Z. Sociophysical models of theory of innovations: Monograph. Ufa: RIK UGATU, 2017.-p.174. (in Russian).

[8] Brealey R., Myers S. Principles of corporate finance. Moscow: Olympbusiness. 1997.

[9] Renegar J. Linear programming, complexity theory and elementary functional analysis (1995) p 279-351, School of Operations Research and Industrial Engineering, Cornell University, E\&TC Building, Ithaca, NY 14853-3801, United States

[10] O'Leary D.P. Symbiosis between linear algebra and optimization,(2000) p 447-465 Department of Computer Science and Institute for Advanced Computer Studies, University of Maryland, College Park, MD 20742, USA

[11] Gardner R. Kantorovich L.V. The Price Implications of Optimal Planning, Journal of Economic Literature. 1990, 28 (2), p. 638-648. 